\title{
The Prevalence and Risk Factors for Potential Oral Malignant Disorders in a Middle Aged North Indian Population
}

\section{AASTHA JAIN*1, BHUVAN SHARMA²}

INTRODUCTION: The menace of oral cancer has become a public health concern and its prevalence is increasing with every passing day, making it the sixth most common cancer across the globe.

OBJECTIVE: To evaluate the prevalence and risk factors for potential oral malignant disorders in a middle aged north Indian population.

MATERIALS AND METHODS: This Cross-sectional study was carried out on 1260 individuals in Delhi and NCR. A questionnaire was created to record information about socio demographic traits, oral hygiene routines, threat associated to oral probable malignant disord ers. The Oral Mucosal lesions were examined by professionals. Results. The Overall Prevalence of Potential oral malignant disorders was found to be with oral submucous fibrosis (6.09\%) found in a greater extent and erythroplakia (0.15\%)found to be lesser.

RESULTS: It was documented that $11.48 \%$ of the Northern Indian Population which suffered from oral malignant lesions, with the prevalence rates of leukoplakia in 3.01\%, Lichen Planus in $1.42 \%$ and lowest being erythroplakia in $0.15 \%$ of the subjects. The prevalence of oral malignant lesions among males was found to be higher(12.8\%) as compared to females p value $<0.0001$. No significant difference was found between categories of socio-economic status, tooth brushing methods ,brushing frequency with prevalence of oral malignant disorders

CONCLUSION: The Study augments an interrelation between tobacco and areca nut consumption with oral probable malignant disorders. An interrelation of oral probable malignant disorders with diabetes and BMI was confirmed by this study.

KEYWORDS: Malignant, Leukoplakia, North Indian, OSMF.

\section{INTRODUCTION}

Oral Cancer is evidently a major concern which is increasing considerably around the globe. Oral and pharyngeal Cancer grouped together is the sixth most common cancer in the world. ${ }^{1}$ Oral Cancer sometimes has predisposing factors, giving rise to visible clinical manifestations which initially are seen as noncarcinogenic initially and are often known as precancerous. The commonest oral probable malignant lesions are leukoplakia, erythroplakia, and oral submucous fibrosis. A large number of these oral mucousal lesions have a tendency to take a malignant turn. The Malignant transformations of oral mucosal lesions are as followed lekoplakia, erythroplakia, and sub mucous fibrosis are well documented. ${ }^{2,3}$

Tobacco has been considered as a prime etiological factor in the initiation of the malignant disorders with variety of written text to hold in validation. ${ }^{4}$ In Asians; the root cause of probable malignant lesions is due to cigarette smoking, excess alcohol intake, and areca quid chewing. ${ }^{5}$ The other disposing factors being Body Mass Index, diabetes and certain dietary preferences like low vegetable inclusion, or lesser fruit incorporation contributes for the development independently acting factors of oral malignant disorders. ${ }^{6}$

Oral potentially malignant disorders and its sequelae may cause heavy deterioration in the Quality of life as the disease is too expensive on the pocket of the society. Research has shown that a single cause of oral cancer cannot be pointed out and it results from a variety of factors that have their effect over a period of time. The most important risk factors for the potential oral premalignant disorders are tobacco use (in any form) and alcohol consumption and up to $75 \%$ of oral cancers could be attributed to their misuse. ${ }^{7}$

Since the use of risk factors is evident in the society especially in the form of tobacco/alcohol use, the present study aimed to record and evaluate the Prevalence and risk factors for Potential oral malignant disorders in a middle aged north Indian population and present in on the global scenario.

\section{MATERIALS AND METHODS}

A cross -sectional study was conducted in Delhi NCR through a survey conducted in various oral health screening/ treatment camps organized in the month of October 2018- February 2019. After obtaining an ethical clearance from the institutional review board, the study participants were duly explained about the study objectives and a written consent was obtained from them.

A prevalence of $35 \%$ oral malignant disorders was found during the pilot study on 25 people. Upon applying 
statistical analysis using the open epi software, a minimal sample size of 465 subjects was found to be appropriate for this study. It is to be noted that the participants of this pilot study were not included in the main survey and the study assessment was primarily for sample size estimation and proper execution of the main study. To incorporate maximum sample inclusion and to compensate for incomplete data and those unwilling to participate in the study, a total number of 1260 people were included in this study via convenience sampling. The age group for the study was chosen between $25-65$ years.

The inclusion criteria was above 18 years as they could legally give consent on participation in the study. Exclusion criteria included participants who did not wish to be a part of the study. Data was collected through a pre-validated questionnaire adapted and modified from Kumar S et al. ${ }^{8}$ and consisted of five sub -sections. The first contained data regarding Socio demographic profile, Socio economic status (based on kuppuswamy scale), Age and gender. A total of 1260 participants were included in the study and the data obtained from them was analysed.

The second sub-section focused on the oral hygiene and the preventive measures taken to maintain it. The adverse oral habits, detailed noting of the quantified amount, consumption was registered. The third subsection emphasised on adverse oral habits which majorly consisted on data including tobacco chewing, Areca Nut, and alcohol consumption. The participants were divided into ever chewers and never chewers.

Examinations were carried out by two observers, who were duly standardized prior to the study. Descriptive statistics was applied and the chi-squared test (for qualitative data) and independent samples t-test(for quantitative data) was applied.

\section{RESULTS}

The study group was divided amongst Males (57.8\%) and Females (42.1\%). A Greater portion belonged to the middle class $(35.5 \%)$ or lower class $(34.6 \%)$ divisional percentage based on their socioeconomic status . $70.6 \%$ Inclination by the population which is a major numeric value was leading by using a toothbrush. (Table 1 )

It was documented that $11.48 \%$ of the Northern Indian Population which suffered from oral malignant lesions, with the prevalence rates of leukoplakia in 3.01\%, Lichen Planus in $1.42 \%$ and lowest being erythroplakia

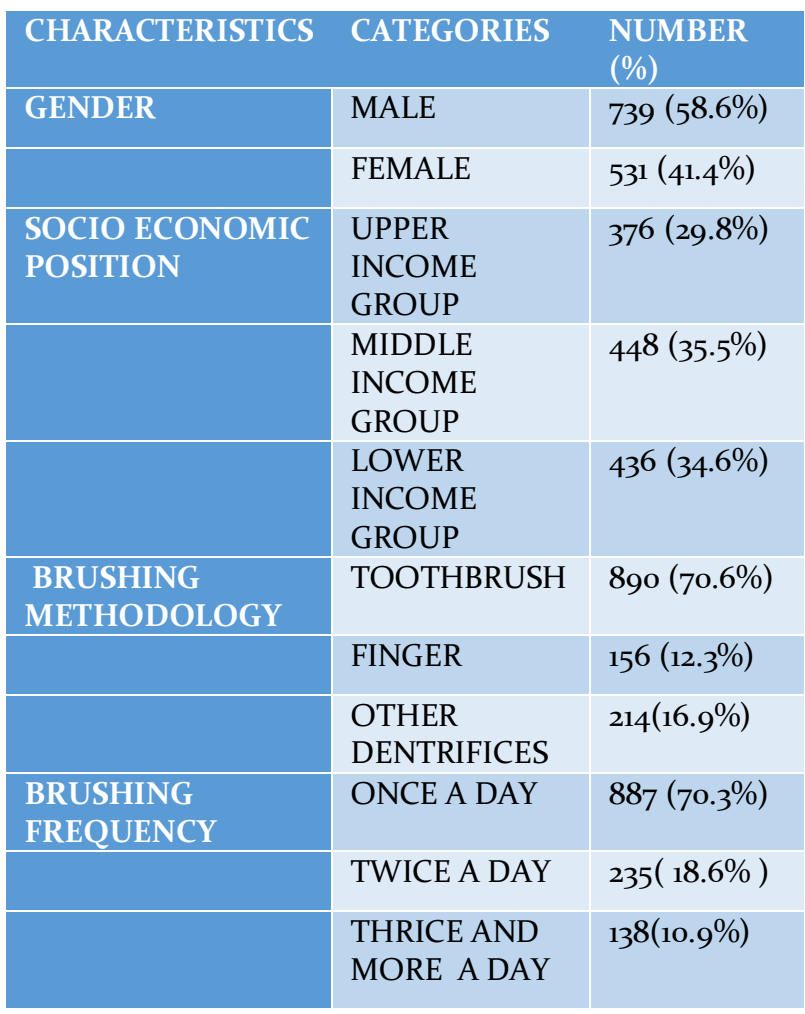

Table 1. Socio demographic and oral hygiene inclination and maintenance by the subjects.

in $0.15 \%$ of the subjects. (Table 2 )

\begin{tabular}{|c|c|}
\hline PREVALENCE & NUMBER \\
\hline & $\%$ \\
\hline OSMF & $\mathbf{8 7}$ \\
\hline LEUKOPLAKIA & $\mathbf{6 . 9 0} \%$ \\
\hline LICHEN PLANUS & $3 \mathbf{8}$ \\
& $\mathbf{3 . 0 1} \%$ \\
\hline ERYTHROPLAKIA & $\mathbf{1 8}$ \\
& $\mathbf{1 . 4 2} \%$ \\
\hline TOTAL & $\mathbf{0 2}$ \\
\hline & $\mathbf{0 . 1 5 \%}$ \\
\hline & $\mathbf{1 4 5}$ \\
\hline
\end{tabular}

Table 2. Prevalence of oral probable malignant disorders in the northern Indian Population

The prevalence of oral malignant lesions among males was found to be higher(12.8\%) as compared to females $\mathrm{p}$ value <0.00o1. No significant difference was found between categories of socio-economic status, tooth brushing methods, brushing frequency with prevalence of oral malignant disorders. A predominance of $26 \% \mathrm{p}$ value < 0.0001 of oral probable malignant disorders individuals and tobacco consumption $22.9 \%$ compared to the never consumers. No significant difference was reflected on the observation a much higher Prevalence 
of oral malignant probability was in the subjects who had taken an appointment and dully visited the dentist and willingly taken the right treatment like wearing prosthesis. [p value $<$ o.0oo1, (Table No 3)]

\begin{tabular}{|c|c|c|c|c|}
\hline FACTORS & CATEGORIES & $\begin{array}{c}\text { ORAL } \\
\text { PROBABLE } \\
\text { MALIGNANT } \\
\text { DISORDERS } \\
\text { PRESENT N\% }\end{array}$ & $\begin{array}{c}\text { ORAL } \\
\text { PREVALENCE OF } \\
\text { THE MALIGNANT } \\
\text { LESIONS ABSENT } \\
\text { N \% }\end{array}$ & P VALUE \\
\hline \multirow[t]{2}{*}{ GENDER } & Male & $88(13 \cdot 5 \%)$ & $651(86.5 \%)$ & $<0.0001$ \\
\hline & Female & $57(12.28 \%)$ & $464(87.72 \%)$ & \\
\hline \multirow[t]{3}{*}{$\begin{array}{c}\text { SOCIOECONOMIC } \\
\text { STATUS } \\
\end{array}$} & Upperclass & $5^{8}(18.2 \%)$ & $318(81.8 \%)$ & \\
\hline & Middle class & $40(9.8 \%)$ & 408(90.2\%) & 0.375 \\
\hline & Lower class & $47(12.01 \%)$ & $389(88 \%)$ & \\
\hline \multirow[t]{3}{*}{$\begin{array}{l}\text { TOOTH BRUSH } \\
\text { METHOD } \\
\end{array}$} & Tooth brush & $75(10.4 \%)$ & $715(89.6 \%)$ & \\
\hline & Finger & $46(15 \cdot 4 \%)$ & $290(84 \cdot 3 \%)$ & 0.481 \\
\hline & Others & $24(21.8 \%)$ & $110(78.2 \%)$ & \\
\hline \multirow[t]{3}{*}{$\begin{array}{c}\text { BRUSHING } \\
\text { FREQUENCY } \\
\end{array}$} & Once & $64(7 \cdot 77 \%)$ & $823(92.23 \%)$ & \\
\hline & Twice & $43(22.3 \%)$ & $191(77 \cdot 7 \%)$ & 0.135 \\
\hline & Thrice & $38(38 \%)$ & $100(62 \%)$ & \\
\hline \multirow[t]{2}{*}{$\begin{array}{c}\text { ALCOHOL } \\
\text { CONSUMPTION } \\
\end{array}$} & Ever consumer & $53(22.2 \%)$ & $238(77 \cdot 7 \%)$ & \\
\hline & $\begin{array}{c}\text { Never } \\
\text { consumer }\end{array}$ & $92(10.4 \%)$ & $877(89.6 \%)$ & 0.046 \\
\hline \multirow[t]{2}{*}{ TOBACCO } & Ever consumer & $63(22.9 \%)$ & $275(78.73 \%)$ & \\
\hline & $\begin{array}{c}\text { Never } \\
\text { consumer }\end{array}$ & $82(9.76 \%)$ & $840(89.8 \%)$ & 0.129 \\
\hline \multirow[t]{2}{*}{ ARECA NUT } & Ever consumer & $67(26.3 \%)$ & $254(73 \cdot 5 \%)$ & \\
\hline & $\begin{array}{c}\text { Never } \\
\text { consumer }\end{array}$ & $78(9.0 \%)$ & $861(91 \%)$ & $<0.001$ \\
\hline \multirow[t]{2}{*}{ BETEL NUT } & Ever consumer & $60(21.27 \%)$ & $282(78.73 \%)$ & \\
\hline & $\begin{array}{c}\text { Never } \\
\text { consumer }\end{array}$ & $85(10.2 \%)$ & $833(89.70 \%)$ & $<0.001$ \\
\hline
\end{tabular}

Table 3. Interrelations of sociodemographic traits, oral hygiene maintenance and adverse oral Habits with oral probable malignant disorders

\section{DISCUSSION}

The prime aim and objective of this study was to document to record and evaluate the prevalence and risk factors for potential oral malignant disorders in a middle aged north Indian population and present in on the global scenario. The backbone of the study was the large size of subjects included in the study so that the results could be extrapolated for the general population.

It was revealed that the prevalence of total oral malignant lesions was $11.48 \%$, out of which the most prevalent lesion was OSMF $(6.90 \%)$ and the least prevalence was erythroplakia (0.15\%) and these figures were in agreement to the results of the study conducted by Chung et al. ${ }^{9}$ (overall prevalence rate 12.7\%) and
Amarasinghe AAHK et al. $^{10}$ (11.3\%). The prevalence of oral probable malignant lesions has a diversified percentage when seen on a global platform. In the current study males are at a higher risk of developing such potential oral malignant disorders as compared to females and this is supported by Nair et al. ${ }^{11}$ Such high risk among males can be attributed to the greater intake of tobacco in males which makes them fall in a high threat zone to develop such lesions.

The results of the present study revealed an inverse relationship between body mass index and the development of oral probable malignant disorders which is in agreement with Kumar S et al. ${ }^{8}$ and Thomas et $a .^{13}$ It is stated that a reasons for the development of 
oral potentially malignant disorders can be also due to immune dysfunction and hormonal imbalance in one's body, which can arise from an increase/decrease in one's BMI.

The study has certain limitations one of which is that the diagnosis of oral malignant lesions was made on presumptive tests provided in textbooks, solely on the clinical manifestations and clinical examination. No Biopsy or confirmatory tests were conducted among the examined subjects. Another limitation is the the societal pressure faced by the women as they cannot reveal their adverse oral habits and hence, leads to underreporting of data. In the end, although many measures were taken to make the current study bias and error free, any inadvertent human error that could have crept in and altered the results cannot be denied, although the chances of such are miniscule and would not affect the results to a greater extent.

\section{CONCLUSION}

Oral probable malignant disorders generally have a tendency to turn into malignancy. The overall Prevalence of oral malignant disorders in the present study was found to be $(11.48 \%)$ with the maximum prevalence of Oral Submucous Fibrosis. Dietary influence are the reflectors in ones immune response as they attribute to every cells well being, one should not necessarily focus only on medication or treatment but dietary form a crucial aspect too. Diabetes and B.M.I were inversely proportional which is self explanatory pertaining due to the socioeconomic status. The Importance of Pre-screening can be established for the increase in survival rates and life expectancy rates by which the spread and progression of Oral Malignant Lesions and disorders would reduce marginally by educating on the preventive measures and precautions .Awareness will lead to prevention and further the cessation of adverse oral habits which will change the scenarios of the factors which will make the probable malignant disorders vanish.

\section{REFERENCES}

1. Warnakulasuriya S. Global epidemiology of oral and oropharyngeal cancer. Oral Oncol. 2009;45(4-5):309-16.
2. Kumar G K, Abidullah M, Elbadawi L, Dakhil S, Mawardi H. Epidemiological profile and clinical characteristics of oral potentially malignant disorders and oral squamous cell carcinoma: A pilot study in Bidar and Gulbarga Districts, Karnataka, India. J Oral Maxillofac Pathol 2019;23:90-6

3. Messadi DV. Diagnostic aids for detection of oral precancerous conditions. Int J Oral Sci. 2013 Jun; 5(2): $59-65$

4. Sridharan G. Epidemiology, control and prevention of tobacco induced oral mucosal lesions in India. Indian J Cancer 2014;51:80-5

5. Hernandez BY, Zhu X, Goodman MT, Gatewood R, Mendiola P, Quinata K, et al. Betel nut chewing, oral premalignant lesions, and the oral microbiome. PLoS One. 2017; 12(2): eo172196.

6. Kumar A, Bindal R,. Shetty DC, Singh HP. Primary oral malignant melanoma: Clinicopathological series of four cases. Dent Res J (Isfahan). 2012 May-Jun; 9(3): 338-344.

7. Takezaki T, Hirose K, Inoue M, Hamajima N, Kuroishi T, Nakamura S, et al. Tobacco, alcohol and dietary factors associated with the risk of oral cancer among Japanese. Jpn J Cancer Res. 1996;87:555-62.

8. Kumar S, Debnath N, Ismail MB, Kumar A, Kumar A, Badiyani BK, et al. Prevalence and Risk Factors for Oral Potentially Malignant Disorders in Indian Population. Advances in Preventive Medicine 2015;2015:208519.

9. Chung $\mathrm{CH}$, Yang $\mathrm{YH}$, Wang TY, Shieh TY, Warnakulasuriya S. Oral precancerous disorders associated with areca quid chewing, smoking, and alcohol drinking in southern Taiwan. J Oral Pathol Med 2005;34:460-6.

10. Amarasinghe AAHK, Usgodaarachchi US, Johnson NW, Warnakulasuriya S. High Prevalence of Lifestyle Factors Attributable for Oral Cancer, and of Oral Potentially Malignant Disorders in Rural Sri Lanka. Asian Pac J Cancer Prev, 19 (9), 2485-92.

11. Nair DR, Pruthy R, Pawar U, Chaturvedi P. Oral cancer: Premalignant conditions and screening - an update. J Can Res Ther 2012;8, Suppl S2:57-66.

12. Thomas G, Hashibe M, Jacob BJ et al. Risk factors for multiple oral premalignant lesions. International Journal of Cancer 2003; 107(2):285-91. 
Source of support: Nil, Conflict of interest: None declared

Cite this article as:

Jain A, Sharma B. The Prevalence and Risk Factors for Potential Oral Malignant Disorders in a

Middle Aged North Indian Population. Int Healthc Res J. 2019;3(3):123-127.

https://doi.org/10.26440/IHRJ/0303.06247

AUTHOR AFFILIATIONS:

1. BDS, MDS (Oral and Maxillofacial Radiology), RD Dental Clinic, Greater Noida

2. BDS, Private Practitioner and Dental Consultant, SK Dental Clinic, Muradnagar

Contact corresponding author at: docjain.azk@yahoo.co.in 